\title{
Voting Procedures and Parliamentary Representation in the European Parliament
}

\author{
Siim Trumm
}

\begin{abstract}
Parliamentary representation is a fluid concept. Yet, while the behaviour of elected representatives during roll call votes has been widely analysed, we know little about how parliamentarians act when their individual voting choices are not made public. This paper explores the relationship between voting procedures and the likelihood that Members of the European Parliament prioritise the interests of their EP party group versus the interests of their national party. Using an original survey, I find that MEPs are more likely to prioritise the interests of their national party over those of their EP party group when voting by show of hands or electronically, as opposed to by roll call. Moreover, this voting procedure effect is particularly salient among MEPs elected from 2004/07 accession countries.
\end{abstract}

Keywords: voting procedures, representation, European Parliament, voting behaviour

\section{Published version}

Trumm, S. 2015. Voting Procedures and Parliamentary Representation in the European Parliament. Journal of Common Market Studies, 53/5: 1126-1142. 


\section{Introduction}

The European Parliament (EP) has undergone major changes since its establishment. The institution's purview has broadened and its powers have strengthened since its conception as the Common Assembly of the European Coal and Steel Community; it has evolved from a consultative body into one of the more powerful institutions within the European Union (EU) (Hix and Hoyland, 2013; Kreppel, 2002; Scully, 2005). Given that the Members of the European Parliament (MEPs) are now able to enact legislation in a wide range of policy sectors, it is vital that we understand MEPs' attitudes and voting behaviour because it offers insight into the kind of parliamentary representation they provide (Farrell and Scully, 2007; Hix et al., 2007; Scully et al., 2012). For example, whether MEPs' main loyalty lies with their national party or their EP party group has significant repercussions for the EP's ability to provide supranational representation for European citizens.

While numerous studies indicate that national parties are MEPs' primary principals (e.g., Coman, 2009; Hix et al., 2007; Ringe, 2010), the contemporary interpretation of MEPs' voting choices derives from analyses of roll call votes. At the same time, roll call votes do not appear to be representative of parliamentary voting occasions at large and include a degree of 'selection bias' (Carrubba et al., 2006; Hug, 2010; Thiem, 2006; Yordanova and Mühlböck, 2014), ${ }^{1}$ raising questions about the ability of roll call analyses to offer a complete picture of MEPs' parliamentary behaviour. If MEPs' behaviour during roll call is not representative of all voting occasions, it is important that we consider whether and how MEPs' behaviour varies across different types of voting procedures.

This paper studies the presence and direction of the voting procedure effect in MEPs' suggested voting behaviour, and it looks at the extent to which MEPs believe that they are influenced by the choice of the voting procedure. ${ }^{2}$ It does so by comparing MEPs' selfperceived likelihood of defecting from the voting instructions of their EP party group if there is a conflict with the voting instructions of their national party when voting by roll call, show of hands, or electronically. ${ }^{3}$ I advance two main arguments about MEPs' behaviour during the different voting occasions. First, building on previous studies of roll call vote requests and the level of interest that different actors show in monitoring MEPs' roll call voting choices (e.g., Carrubba et al., 2006; Corbett et al., 2011; Thiem, 2006), I argue that MEPs are more

\footnotetext{
${ }^{1}$ Although not all studies support the presence of bias in roll call samples (Hix et al., 2013), there is increasing evidence to show that discrepancies exist between roll call and non-roll call votes in the EP.

${ }^{2}$ For detailed information on the voting procedures used in the EP, see its Rules of Procedure (2014).

${ }^{3}$ The term 'national party' refers to the national party and its leadership in MEPs' home country, encompassing the domestic 'party in central office' and the domestic 'party in the public office' (Katz and Mair, 1993).
} 
inclined to defect from their EP party group when voting by show of hands or electronically, as opposed to roll call. Second, building on insights about the differences between the role and self-perceptions of MEPs from 2004/07 accession countries and MEPs from pre-2004 member states (EES, 2012; Farrell et al., 2011), I expect this voting procedure effect to be more pronounced among MEPs from the accession countries.

I evaluate these arguments using an original MEP survey conducted in 2011, and find that a significant voting procedure effect is present in MEPs' perceptions of their approach to representation. Nearly $30 \%$ of MEPs claim to behave differently when voting by non-roll call methods, and the vast majority of these MEPs consider themselves to be more likely to defect from their EP party group in favour of their national party. Moreover, this pattern is more salient among MEPs from 2004/07 accession countries; around 50\% of these MEPs perceive to change their approach to representation when voting by show of hands or electronically instead of roll call.

These findings are important for two reasons. First, I demonstrate that we should be cautious regards to the inferences we draw about MEPs' voting behaviour from the study of roll call votes. While MEPs' perceptions of their voting behaviour across the different types of voting procedures are consistent with the findings of the roll call-based literature - i.e., MEPs' primary loyalty lies with their national party -, analyses based exclusively on roll call votes are likely to overemphasise the degree of loyalty that MEPs show to the supranational EP party groups. The findings presented here indicate that MEPs consider themselves to more likely defect from their EP party group when voting by non-roll call. Therefore, even though MEPs' loyalties follow similar patterns in roll call and non-roll call settings, it is important that we acknowledge the differences between the different types of voting occasions when interpreting how MEPs approach parliamentary representation.

Second, these findings highlight a potential impact of the 2004/07 enlargements on the legislative decision-making in the EP. Whereas existing roll call analyses find only small differences between the voting behaviour of MEPs from 2004/07 accession countries and MEPs from pre-2004 member states (Coman, 2009; Hix and Noury, 2009), the findings presented here show that a larger proportion of MEPs from 2004/07 accession countries change their approach to representation as a result of a vote being taken by non-roll call instead of roll call. Thus, differences between how these groups behave in the EP may be more significant than previously acknowledged. 


\section{Competing Loyalties and Voting Procedures}

MEPs have three more salient loyalties when carrying out their duties in the EP: their EP party group, national party, and electorate (Hix et al., 2007; Hix and Hoyland, 2011). For example, national parties have the ability to influence MEPs' behaviour primarily because of their significance in the electoral arena. Their power to decide who is allowed to stand as a party candidate and where candidates are placed on the party list has implications for who gets elected. By contrast, EP party groups have no real control over MEPs' chances to get reelected, but they hold significant power over MEPs' ability to influence policy-making in the EP. Among else, they determine the leadership positions within the EP (Corbett et al., 2011; Hix et al., 2007). Given that these principals represent different stakeholders, how MEPs respond to the contrasting expectations of these actors gives us valuable information about the kind of representation they provide. Arguably, the EP would be better able to represent European-wide interests if MEPs were to prioritise the positions of their supranational EP party group.

Given the growing importance of the EP, it is unsurprising that MEPs' voting choices have been the subject of numerous empirical studies. From these studies, we know that national parties remain as MEPs' primary principal, and that both national parties and EP party groups enjoy higher degrees of loyalty than national electorates (e.g., Coman, 2009; Hix et al., 2007; Lindstädt et al., 2011; Roland, 2009). ${ }^{4}$ Thus, a clear preference ranking is present regarding the loyalties that shape MEPs' voting choices and representation in the EP.

The conventional wisdom on MEPs' parliamentary behaviour and how they approach representation, however, derives from analyses of roll call votes. This is hardly surprising, as roll call votes, despite still constituting only a minority of the parliamentary voting occasions, remain the only votes where individual MEPs' voting choices are recorded and publicised. Their unique public nature offers scholars valuable insight into MEPs' revealed voting behaviour. At the same time, relying exclusively on roll call analyses to document how MEPs approach representation in the EP can only offer a complete picture of MEPs' parliamentary behaviour if it is consistent across roll call and non-roll call votes.

There are, however, reasons to believe that this might not be the case. In addition to the fact that roll call votes are unique in their public nature, it is increasingly clear that roll call vote samples are not representative of all parliamentary voting occasions. Using novel

\footnotetext{
${ }^{4}$ A notable exception to these patterns is Mühlböck (2012), who shows that MEPs from governmental parties of the EU-15 were more likely to follow their EP party group than their national party's minister in the Council when voting on codecision legislation between 1999 and 2009.
} 
datasets of all proposals voted on in the EP, scholars have shown that roll call votes tend to be called for unequally by the different EP party groups, originate in just a few committees, and are more likely to be requested by the EP party groups when national interests are expected to be less vocal (e.g., Carrubba et al., 2009; Finke and Thiem, 2010; Hug, 2010, 2012). Thus, salient discrepancies exist between samples of roll call and non-roll call votes. While this does not necessarily mean that MEPs approach representation differently when voting by non-roll call, such a possibility appears increasingly plausible. ${ }^{5}$

It is worth noting that the recent requirement of all final legislative votes to be taken by roll call limits the extent to which roll call and non-roll call samples can differ. However, roll call votes are still used for a minority of voting occasions and proposals originating from some committees that engage with salient policy areas such as Internal Market and Consumer Protection are rarely voted on by roll call (Carrubba et al., 2006; Gabel and Carrubba, 2004). This indicates that non-roll call is unlikely to be used only for the unimportant votes. ${ }^{6}$

\section{MEPs' Behaviour Is Influenced by the Voting Procedure Used}

The public nature of roll call votes means that interested actors can scrutinise MEPs' voting choices. In contrast, this is much more problematic for show of hands voting (one has to observe an MEP's hand signal) and nearly impossible for electronic voting (one has to see which button an MEP presses). This means that roll call votes are effectively the only voting occasions where MEPs' actual voting choices can be monitored and sanctioned.

EP party groups and national parties, however, differ in their use of roll call voting information to sanction or reward MEPs' behaviour. Whereas EP party groups show considerable interest in their members' voting choices during roll call, MEPs remain distant from their national parties at home who scrutinise their members' roll call voting choices only when the issue in consideration is of particular interest to them (Corbett et al., 2011; Hix et al., 2007; Ladrech, 2007). Thus, the heightened ability to punish and reward MEPs on the basis of their voting choices by virtue of a vote being taken by roll call is considerably more salient to EP party groups.

\footnotetext{
${ }^{5}$ In fact, there is evidence from roll call-based literature to offer indirect support for it. Hoyland (2010), looking at roll call votes in the pre-2004 EP, shows that procedural effects exist in MEPs' voting patterns as they adopt different positions vis-à-vis second reading codecision amendments and resolutions.

${ }^{6}$ Moreover, the MEP survey indicates that there is little difference in how much pressure the EP party groups and national parties put on MEPs to cast a particular voting choice when a vote is taken by roll call or non-roll call. The latter do not appear to be treated as notably less important.
} 
Moreover, voting in the EP takes place by show of hands as a general rule, with roll call votes having to be requested by a political group or at least $40 \mathrm{MEPs}^{7}$ As a result, it is EP party groups who are the driving force behind roll call requests (Carrubba et al., 2006; Saalfeld, 1995; Thiem, 2006), and there is a general consensus among scholars that the decision to request a roll call vote is a strategic one (Kreppel, 2002). Three main theoretical explanations of roll call vote requests have been proposed in recent years: to discipline party members (Carey, 2009; Carrubba et al., 2008), signal policy positions (Ainsley and Maxwell, 2010; Thiem, 2006), and expose divisions in competing parties (Saalfeld, 1995). All these imply a desire for high levels of intra-group unity.

From MEPs' point of view, the different reasons for roll call requests create slightly different motivations to follow their EP party group. On the one hand, the disciplining objective - i.e., collecting voting information to accurately dole out reward and punishment (Carrubba et al., 2008) - almost compels MEPs to follow their EP party group. They know that EP party groups take heightened interest in their voting choices, and that there is an increased likelihood of benefiting from loyalty (and suffering from disloyalty). This selfinterested incentive to follow their EP party group is simply not present during non-roll call. On the other hand, the signalling and exposing objectives - i.e., displaying popular positions of own party and unpopular positions of others as well as exposing intra-party dissent within competitors (Saalfeld, 1995) - exert a more subtle influence on MEPs. As fragmented party groups face considerable barriers to accomplish their policy goals and intra-party dissent garners negative media attention (Ainsley and Maxwell, 2012), MEPs are likely to feel more obliged to follow their EP party group during roll call to avoid embarrassment to the party and to maintain positive relationships with co-partisans. Moreover, it is in MEPs' interest to be on good terms with their EP party group, as their EP party group's support is likely to be needed to further MEPs' own personal policy ambitions. Taken together, the public nature of roll call votes creates different behavioural implications for MEPs; namely, greater pressure to follow their EP party group.

The question that remains is why MEPs would want to behave differently when this pressure is not present? After all, the unobservable nature of non-roll votes means that MEPs' voting choices will simply go unnoticed and there is little potential for being rewarded by one's national party. That being said, national parties have narrower ideological foundations than the EP party groups. As such, it is unsurprising that MEPs feel ideologically closer to the

\footnotetext{
${ }^{7}$ Roll call is the default procedure for electing or rejecting the Commission, voting on the motion of censure on the Commission, and for final legislative acts (European Parliament, 2014).
} 
former (EES, 2012; Farrell et al., 2011). With MEPs' policy positions naturally aligning more closely with those of their national party, as opposed to those of their EP party group, it is the former that they are more likely to want to follow when there are no external pressures to act otherwise (i.e., when voting by non-roll).

H1: If MEPs receive conflicting voting instructions from their EP party group and their national party, MEPs are more likely to defect from their EP party group when voting by show of hands or electronically, as opposed to roll call.

While non-roll call voting should be characterised by MEPs' weaker loyalty to their EP party group than roll call voting, MEPs from 2004/07 accession countries should be particularly receptive to this voting procedure effect. On the one hand, MEPs from 2004/07 accession countries should be more inclined to follow their EP party group during the public roll call votes. Borrowing from literature on the behaviour of elected representatives in the national context where new MPs are usually found disproportionately loyal to their party, the greater loyalty of these MEPs is likely to occur because they still want to show themselves to their EP party group and the general public as parliamentarians who fit in the institution and follow its supranational ideal (e.g., Cowley and Stuart, 2012). In other words, they are more eager to be perceived as 'good citizens'. Unlike the 'hidden' non-roll call votes, the public nature of roll call voting allows for such a presentation of oneself through greater loyalty to one's EP party group. ${ }^{8}$

On the other hand, when MEPs are able to cast their unfiltered preferences (i.e., nonroll call voting), MEPs from 2004/07 accession countries are likely to find it more desirable to prioritise their national party. Recent surveys show that MEPs from 2004/07 accession countries are more likely to prioritise their national identity over the European identity than MEPs from pre-2004 member states, and assign greater importance to representing national interests (EES, 2012; Farrell et al., 2011). Seeing their role and self-perceptions more through the prism of nationality, defecting from their supranational EP party group in favour of their national party should be more natural. Moreover, national parties remain more dominant in the electoral arena when comparing 2004/07 accession countries with pre-2004 member states. Politicians in 2004/07 accession countries rely more heavily on the support of their national party (and its leadership) to become party candidates, but also tend to receive more financial and administrative support from their national party during campaigns (CCS, 2013;

\footnotetext{
${ }^{8}$ This expectation is also in line with roll call voting data from the $7^{\text {th }}$ Parliament (VoteWatch, 2014).
} 
EES, 2012; Farrell et al., 2011). As such, MEPs from 2004/07 accession countries are likely to see loyalty to their national party during non-roll call as more natural, as well as an opportunity to repay for its earlier support.

H2: The voting procedure effect is larger among MEPs from 2004/07 accession countries than MEPs from pre-2004 member states.

\section{Using an Original Survey to Capture MEPs' Perceptions}

Since it is nearly impossible to obtain data on MEPs' actual voting choices during roll call and non-roll call voting occasions, a survey of MEPs offers a unique opportunity to tap into MEPs' approach to representation when different voting procedures are used. ${ }^{9}$ The analyses presented here rely on an original survey. MEPs were presented with the pre-defined voting dilemma of receiving contrasting voting instructions from their EP party group and national party. They were then asked about their likelihood of defecting from their EP party group when voting by roll call, show of hands, and electronically; response options ranged from 1 'very unlikely to defect' to 4 'very likely to defect'. ${ }^{10}$ Given how sensitive the issue of defection is, MEPs were invited, but not required, to identify themselves. ${ }^{11}$ This survey design makes it possible to capture any differences that exist in MEPs' self-perceived loyalty to their EP party group vs. national party across the different voting procedures. ${ }^{12}$

As part of data collection, all 736 MEPs who served in the EP as of 01/01/2011 were approached to participate in the survey. It was carried out in an online format with several linguistic choices; the responses of Non-Inscrits and MEPs elected as independent candidates were excluded from the analysis. The final sample includes 181 MEPs, with $32.8 \%$ from 2004/07 accession countries and $67.2 \%$ from pre-2004 member states. ${ }^{13}$ To show that the sample is representative, I used the Duncan index of dissimilarity on the distributions of two

\footnotetext{
${ }^{9}$ While other techniques have been tried - e.g., Heckman selection model by Hug (2012) and natural language processing by Pemstein (2009) -, their ability to correct for bias in roll call scores, by scholars' own accord, remains limited. As such, an MEP survey provides the best proxy (voting-perception) for gaining a comparative insight into MEPs' behaviour during roll call and non-roll call votes.

10 'There are likely to be voting occasions when you receive different voting instructions from your EP political group and your national party. Please tick the appropriate box to indicate how likely you are in such occasions to defect from the EP political group's voting instructions when the vote is taken by roll call, show of hands, and electronically'. Answer: 1 'very unlikely', 2 'unlikely', 3 'likely', 4 'very likely'.

${ }^{11}$ See the online appendix, available at identifying website, for further discussion on the merits of anonymity.

${ }^{12}$ To ensure that MEPs interpret the survey question as intended, they were introduced to the research prior to proceeding with the survey. This was done to avoid the possibility of MEPs mistaking the distinction between roll call vs. show of hands vs. electronic voting with the distinction between final vs. non-final votes, given the increased overlap in voting procedures and types of votes since 2009.

${ }^{13}$ The sample size is in line with response rates of other recent MEP surveys. Whereas the 2009 EES received responses from around $23 \%$ of the elected candidates (EES, 2012), the 2010 EPRG survey got near-full set of responses from approximately $24 \%$ of MEPs (Farrell et al., 2011).
} 
major characteristics - EP party group and EU member state - within the full population of MEPs and the MEP survey sample (see Appendix A). ${ }^{14}$

The reliance on survey data and MEPs' self-reported behaviour offers unique research opportunities, but also calls for caution. Scholars have correctly noted that survey data can be subject to response bias, a prime example of this being the over-reporting of voter turnout (e.g., Ansolabehere and Hersh, 2012). While it is impossible to verify MEPs' self-perceived non-roll call behaviour, there is evidence to support the reliability of the survey findings. Namely, MEPs' reported roll call behaviour follows closely their actual roll call behaviour, and the degree of importance they assigned to representing different stakeholders is highly consistent with corresponding evidence from other recent MEP surveys. ${ }^{15}$ Moreover, survey data complements the more traditional analyses of roll call voting behaviour. ${ }^{16}$ It allows us to explore the structure underlying the attitudes of MEPs that their parliamentary behaviour is based upon (Thomassen et al., 2004). The public nature of roll call votes means that they may not reveal MEPs' pure preferences regarding representation. Instead, these votes may reveal preferences that are filtered through the prism of strategic calculations and paint the picture of MEPs as they want the world to see them. Survey data allows us to explore MEPs' 'unfiltered' preferences. By promising MEPs anonymity, they had no one to please through their responses and no principal to fear, and therefore, MEPs were able to reveal their underlying attitudes regarding parliamentary representation.

\section{Evaluating the Existence of the Voting Procedure Effect}

To determine whether there is a voting procedure effect in MEPs' perceptions of their voting behaviour, I start by examining the rates of defection from their EP party group across the three voting procedures. Table 1 presents the percentage of MEPs who selected each of the responses, as well as the corresponding mean values. Note first that all three mean values are closer to the upper end of the scale, indicating that MEPs claim to more likely defect from than follow their EP party group when there is a conflict with their national party. This fits

\footnotetext{
14 These two characteristics have also been used by the prominent EPRG surveys of 2000, 2006, and 2010 to assess the representativeness of their sample vis-à-vis the full population of MEPs (Farrell et al., 2011).

${ }^{15}$ See the online appendix, available at identifying website, for further discussion on the appropriateness of using self-reported statements to capture MEPs' parliamentary behaviour.

${ }^{16}$ Among else, André and Depauw (2013) and Deschouwer and Depauw (2014) utilised survey data from the cross-national PARTIREP project to explore the parliamentary behaviour of elected representatives, while Andeweg and Thomassen (2005) demonstrated the usefulness of survey instruments to study how MPs' views on representation compare with those of their voters and their own behaviour.
} 
with our understanding that national parties (and not the EP party groups) are MEPs' primary principal.

In addition, Table 1 suggests preliminary support for H1. On average, MEPs claim to be more likely to defect from their EP party group when voting by show of hands (2.96) and electronically (2.95), as opposed to roll call (2.73). ${ }^{17}$ Moreover, only for roll call are 'likely' and 'unlikely' the two most popular response options, indicating that no strong priority is given by MEPs to following their EP party group or national party. When voting by show of hands or electronically, however, there is a clear tendency among MEPs to prefer the interests of their national party; the two most popular response options are 'likely' and 'very likely' for both voting procedures. Therefore, this initial analysis of the survey responses supports the theoretical expectations set out in $\mathrm{H} 1$; on average, MEPs approach non-roll call voting in a less supranational manner.

Table 1. MEPs' Voting-Perceptions across the Voting Procedures

\begin{tabular}{lccc}
\hline & Roll Call & Show of Hands & Electronic \\
\hline Very Unlikely (1) & $7.0 \%$ & $2.8 \%$ & $3.6 \%$ \\
Unlikely (2) & $33.8 \%$ & $30.5 \%$ & $29.3 \%$ \\
Likely (3) & $38.7 \%$ & $34.0 \%$ & $35.7 \%$ \\
Very Likely (4) & $20.4 \%$ & $32.6 \%$ & $31.4 \%$ \\
\hline Mean Score & 2.73 & 2.96 & 2.95 \\
\hline
\end{tabular}

Notes. MEPs' self-perceived likelihood of defecting from their EP party group in favour of their national party during roll call, show of hands, and electronic voting.

Next, I evaluate the presence and magnitude of the differences in individual MEPs' perceived likelihood of defecting from their EP party group when different voting procedures are used. To do so, I compare an MEP's perceived likelihood of defecting from her EP party group during different combinations of voting procedures. ${ }^{18}$ That is, I deduct her likelihood of defecting from the voting instructions of her EP party group when one type of a voting procedure is used from her likelihood of defecting when voting by another. This results in three measures of difference; each compares how an MEP's perceived likelihood of defecting from her EP party group varies when two different voting procedures are used. Since MEPs' voting-perceptions are measured on a 4-point scale, the difference measure ranges from -3 to +3 ; higher values indicate a greater likelihood of defecting from one's EP party group when voting by the latter procedure in the combination (see Table 2).

\footnotetext{
${ }^{17}$ The differences between MEPs' likelihood of defecting from their EP party group when voting by show of hands vs. roll call and electronically vs. roll call are statistically significant at $\mathrm{p}<.01$.

${ }^{18}$ Roll call vs. show of hands, roll call vs. electronically, and show of hands vs. electronically.
} 
Table 2 presents MEPs' self-perceived likelihood of defecting from their EP party group when different voting procedures are used, as well as the t-statistics associated with those likelihoods. It highlights the presence and direction of the individual-level effect that results from the reliance on different voting procedures. Although most MEPs indicate that they are equally likely to defect from their EP party group when voting by roll call or non-roll call, $29.1 \%$ report that they approach representation differently when voting by roll call vs. show of hands and $24.3 \%$ claim that they behave differently when voting by roll call vs. electronically. Moreover, the corresponding two-tailed p-values are statistically significant at $\mathrm{p}<.01$, as shown by the respective t-statistics of -4.31 and -4.69 . Therefore, a substantial minority of MEPs claim they approach representation differently when voting by show of hands or electronically instead of roll call.

Table 2. Changes in Individual MEPs' Voting-Perceptions

\begin{tabular}{|c|c|c|c|c|c|c|}
\hline \multirow[b]{2}{*}{ Score } & \multicolumn{2}{|c|}{$\begin{array}{c}\text { Roll Call vs. } \\
\text { Show of Hands }\end{array}$} & \multicolumn{2}{|c|}{$\begin{array}{l}\text { Roll Call vs. } \\
\text { Electronic }\end{array}$} & \multicolumn{2}{|c|}{$\begin{array}{c}\text { Show of Hands vs. } \\
\text { Electronic }\end{array}$} \\
\hline & Count & Percentage & Count & Percentage & Count & Percentage \\
\hline \multicolumn{7}{|l|}{3} \\
\hline 2 & 1 & $0.7 \%$ & & & & \\
\hline 1 & 6 & $4.3 \%$ & 4 & $2.9 \%$ & 5 & $3.6 \%$ \\
\hline 0 & 100 & $70.9 \%$ & 106 & $75.7 \%$ & 131 & $93.6 \%$ \\
\hline-1 & 27 & $19.1 \%$ & 24 & $17.0 \%$ & 4 & $2.9 \%$ \\
\hline-2 & 6 & $4.3 \%$ & 5 & $3.6 \%$ & & \\
\hline-3 & 1 & $0.7 \%$ & 1 & $0.7 \%$ & & \\
\hline
\end{tabular}

T-Statistic $-4.31$ $-4.69$ 0.33

Notes. MEPs' comparative likelihood of defecting from their EP party group in favour of their national party during roll call vs. show of hands, roll call vs. electronic, show of hands vs. electronic voting. Positive scores indicate greater likelihood of defecting during the former voting procedure, 0 refers to an equal likelihood of defecting, and negative scores indicate greater likelihood of defecting during the latter voting procedure.

Moreover, MEP defection follows a pattern. Table 2 indicates that MEPs' perceived likelihood of defecting from their EP party group is greater when voting by non-roll call, as opposed to roll call. In total, $24.1 \%$ of MEPs consider themselves to be more likely to defect from their EP party group when voting by show of hands, as opposed to roll call. In contrast, only $5 \%$ claim to be more likely to defect from their EP party group when voting by roll call, as opposed to show of hands. The same trend is also present for roll call vs. electronic voting, where the respective percentages of MEPs are $21.3 \%$ and 2.9\%. Therefore, of MEPs who perceive a difference to exist in their voting behaviour, as many as $82.9 \%$ (roll call vs. show of hands) and $88.1 \%$ (roll call vs. electronically) use non-roll call voting as an opportunity to 
more frequently prioritise the interests of their national party. Thus, non-roll call voting is characterised by MEPs' weaker loyalty to their supranational EP party group.

\section{Is the Voting Procedure Effect More Salient for 2004/07 MEPs?}

In order to evaluate H2, I replicate this analysis separately for MEPs from 2004/07 accession countries and those from pre-2004 member states. Table 3 presents MEPs' self-perceived mean likelihood of defecting from their EP party group across the three voting procedures for both groups. Note first that the difference in MEPs' self-perceived likelihood of defecting from their EP party group at non-roll call vs. roll call voting is larger for MEPs from 2004/07 accession countries. For these MEPs, this difference is 0.51 for show of hands vs. roll call and electronic vs. roll call voting. Although MEPs from pre-2004 member states are also more likely to defect when voting by show of hands or electronically, as opposed to roll call, the differences are smaller at 0.09 and 0.08. Therefore, the initial analysis supports the theoretical expectation - i.e., voting procedure effect is more pronounced among MEPs from 2004/07 accession countries.

A closer examination of how the more pronounced voting procedure effect among MEPs from 2004/07 accession countries comes about reveals another interesting insight. While these MEPs are more likely to defect from their EP party group than MEPs from pre2004 member states during non-roll call as expected, it is their considerably lower likelihood to defect from their EP party group during roll call that stands out more. While this does not contradict the theoretical expectations regarding the comparative magnitude of the voting procedure effect, the degree to which the latter mechanism is more salient in driving the difference in the voting procedure effect among the two sub-sets of MEPs is surprising and something that future research should explore in more detail.

Table 3. Voting-Perceptions by Split Samples

\begin{tabular}{lcc}
\hline & Pre-2004 & $2004 / 07$ \\
\hline Roll Call & 2.85 & 2.46 \\
Show of Hands & 2.94 & 2.97 \\
Electronic & 2.93 & 2.97 \\
& & \\
$\Delta$ (Show of Hands - Roll Call) & 0.09 & 0.51 \\
$\Delta$ (Electronic - Roll Call) & 0.08 & 0.51 \\
$\Delta$ (Show of Hands - Electronic) & 0.01 & 0.00 \\
\hline
\end{tabular}

Notes. Mean likelihood of MEPs from 2004/07 accession countries and MEPs from pre-2004 member states to defect from their EP party group in favour of their national party when different voting procedures are used. 
Next, I evaluate the presence and magnitude of the differences in individual MEPs' perceived likelihood of defecting from their EP party group when different sets of voting procedures are used. Table 4 summarises the comparative responses of MEPs from 2004/07 accession countries and those from pre-2004 member states. The values presented in Table 4 indicate that a larger percentage of MEPs from 2004/07 accession countries identify a voting procedure effect in their behaviour. Only $51.4 \%$ and $54.1 \%$ of these MEPs are equally likely to defect from their EP party group at roll call vs. show of hands and roll call vs. electronic voting, respectively. The corresponding percentages of MEPs from pre-2004 member states are higher at $79.5 \%$ and $86.8 \%$, respectively. Thus, it is the MEPs from 2004/07 accession countries who appear to be driving the patterns associated with the voting procedure effect.

Table 4. Changes in Individual MEPs' Voting-Perceptions by Split Samples

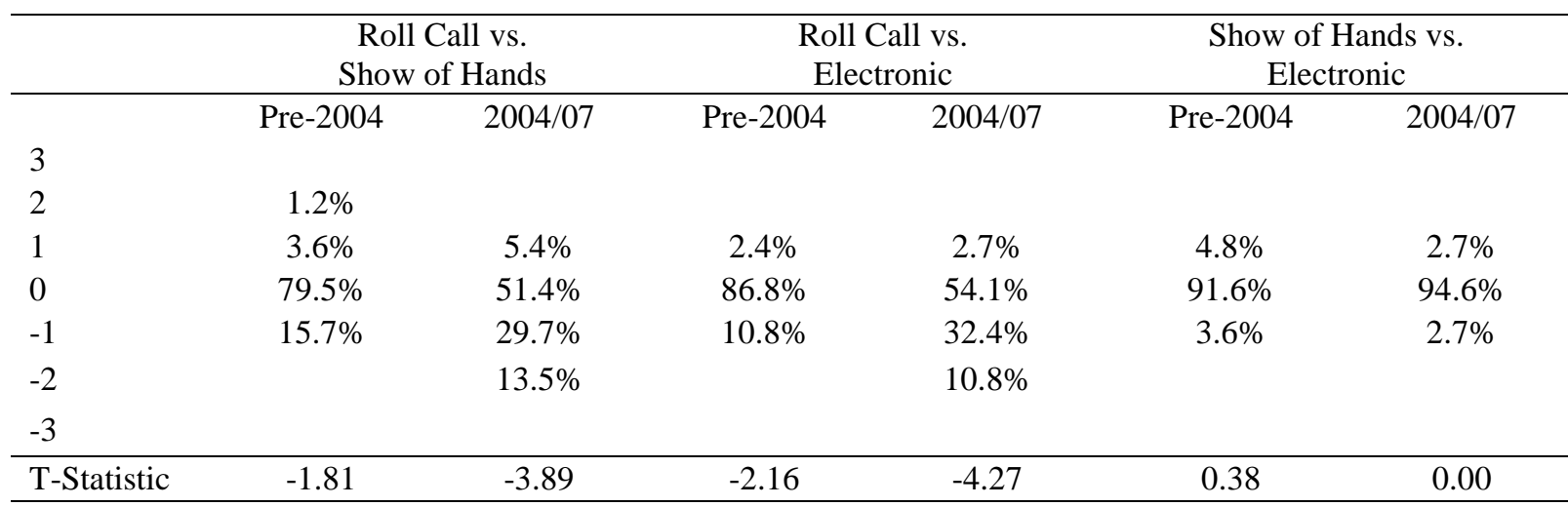

Notes. Comparative likelihood of MEPs from pre-2004 member states and MEPs from 2004/07 accession countries to defect from their EP party group in favour of their national party during roll call vs. show of hands, roll call vs. electronic, show of hands vs. electronic voting. Positive scores indicate greater likelihood of defecting during the former voting procedure, 0 refers to an equal likelihood of defecting, and negative scores indicate greater likelihood of defecting during the latter voting procedure.

The differences between the two sub-groups of MEPs are not, however, limited to the presence of the voting procedure effect. Its magnitude is also more pronounced among MEPs from 2004/07 accession countries. In total, 43.2\% of these MEPs claim to be more likely to defect from their EP party group when voting by show of hands (vs. roll call), and only 5.4\% are more likely to defect during roll call instead. The voting procedure effect is weaker among MEPs from pre-2004 member states, with the respective percentages of MEPs being $15.7 \%$ and $4.8 \%$. The same pattern is also true when comparing MEPs' voting-perceptions during roll call vs. electronic voting. While 43.2\% of MEPs from 2004/07 accession countries are more likely to defect from their EP party group during electronic voting, only $2.7 \%$ claim to be more likely to defect during roll call instead. In contrast, the respective percentages of MEPs from pre-2004 member states are $10.8 \%$ and 2.4\%. Although both sub-groups of MEPs 
show weaker commitments to supranational representation when their voting choices are not made public, the voting procedure effect is more pronounced among MEPs from 2004/07 accession countries.

It is worth noting that this difference may dissipate over time as MEPs from 2004/07 accession countries become more socialised in their new surroundings. That being said, while there is not enough information yet to evaluate how the voting procedure effect evolves over time, there are indications that the behaviour and attitudes of MEPs from 2004/07 accession countries are quite stable. Roll call data from the $7^{\text {th }}$ Parliament and MEP survey data from Farrell et al. (2011) show that 'returning' MEPs from 2004/07 accession countries (i.e., who had served in the $6^{\text {th }}$ Parliament) did not follow significantly different voting patterns or roleperceptions than 'first-time' MEPs from 2004/07 accession countries (i.e., who had not served in the $6^{\text {th }}$ Parliament). ${ }^{19}$ Also, the voting patterns and role-perceptions of 'returning' MEPs during the $7^{\text {th }}$ Parliament had not changed significantly from the $6^{\text {th }}$ Parliament (Farrell et al. 2011; VoteWatch, 2014). Therefore, there are reasons to believe that the pronounced nature of the voting procedure effect among MEPs from 2004/07 accession countries is not just a temporary anomaly, but might describe underlying differences in the parliamentary behaviour of these MEPs. ${ }^{20}$

Overall, the introduction of MEPs from the twelve accession countries appears to have had an impact on representation in the EP. A considerably larger proportion of these MEPs claim to change their approach to representation (in favour of their national party) when show of hands or electronic voting is used, as opposed to roll call, than the proportion of MEPs from pre-2004 member states.

\section{Supplementary Analysis}

The descriptive analyses demonstrated that that many MEPs believe that they behave differently during non-roll call vs. roll call, and that this difference is pronounced among MEPs from 2004/07 accession countries. Ideally, I would explore these differences more systematically, controlling for a range of characteristics that could explain MEPs' willingness to defect. Given that many MEPs did not choose to violate the anonymity of the survey, the data does not allow for an extensive multivariate analysis. However, I am able to provide a first-cut descriptive insight into different MEPs' comparative behaviour. In total, 132 MEPs

\footnotetext{
${ }^{19}$ See also Scully (2005) for a detailed discussion on the limited nature of institutional socialisation in the EP.

${ }^{20}$ Moreover, the MEP survey was purposefully carried out during the $7^{\text {th }}$ Parliament instead of the $6^{\text {th }}$ Parliament to avoid any potential bias associated with the immediate post-accession period.
} 
disclosed which member state they were from, and 117 said which EP party group and national party they belonged to. ${ }^{21}$

Existing research has identified several characteristics that are useful for explaining variation in MEPs' roll call voting behaviour. These include MEPs' role-perception, size and ideology of their EP party group, ballot structure used at the European elections, and whether one's national party is in government or not (e.g., Brzinski, 1995; Hix et al., 2007; Hix and Hoyland, 2011). Using these insights, Table 5 presents six difference of means tests where MEPs' comparative self-perceived likelihood of defecting from their EP party group during three combinations of voting procedures is compared across different sets of MEPs. ${ }^{22}$

Note first that the self-perceived behaviour of MEPs from pre-2004 member states and 2004/07 accession countries is significantly different during roll call vs. show of hands voting and roll call vs. electronic voting. The negative scores of -.42 and -.43 (statistically significant at $\mathrm{p}<.01$ ) indicate that the propensity by which MEPs from 2004/07 accession countries consider themselves to be more likely to defect from their EP party group during non-roll call (vs. roll call) is considerably bigger than that of MEPs from pre-2004 member states.

Table 5. Presence and Direction of Voting Procedure Effect among Different MEPs

\begin{tabular}{|c|c|c|c|c|c|}
\hline & \multirow{2}{*}{$\begin{array}{c}\text { Roll Call vs. } \\
\text { Show of Hands }\end{array}$} & \multirow{2}{*}{$\begin{array}{l}\text { Roll Call vs. } \\
\text { Electronic }\end{array}$} & \multirow{2}{*}{$\begin{array}{l}\text { Show of Hands } \\
\text { vs. Electronic }\end{array}$} & \multicolumn{2}{|c|}{ Duncan Index } \\
\hline & & & & (1) & $(2)$ \\
\hline \multicolumn{6}{|l|}{ MEP } \\
\hline Represent (Europe vs. Nat. Party) & $.01(.16)$ & $-.06(.14)$ & $-.06(.06)$ & .15 & .10 \\
\hline \multicolumn{6}{|l|}{ Country } \\
\hline Entry to the EU (New vs. Old) & $-.42 * * *(.12)$ & $-.43 * * *(.10)$ & $-.01(.05)$ & .15 & .10 \\
\hline Electoral System (Open vs. Closed) & $-.19(.11)$ & $-.14(.10)$ & $.05(.05)$ & .15 & .10 \\
\hline \multicolumn{6}{|l|}{ EP Party Group } \\
\hline Ideology (Anti vs. Pro) & $-.06(.18)$ & $-.06(.15)$ & $-.01(.08)$ & .13 & .10 \\
\hline Size (Small vs. Large) & $.23 *(.11)$ & $.23 * *(.11)$ & $-.01(.82)$ & .13 & .10 \\
\hline \multicolumn{6}{|l|}{ National Party } \\
\hline Government (Yes vs. No) & $.14(.12)$ & $.05(.10)$ & $-.10(.05)$ & .13 & .10 \\
\hline
\end{tabular}

There are also meaningful differences between MEPs based on the size of their EP party group. When comparing the perceived behaviour of MEPs who belong to the larger vs.

\footnotetext{
${ }^{21}$ These sub-samples are reasonably representative of the full population of MEPs (see Table 5).

${ }^{22}$ Note that three ordered logistic models, corresponding to the three combinations of voting procedures, were also constructed to gain a multivariate insight into how the voting procedure effect varies across different MEPs (see the online appendix at identifying website). Although the findings of the multivariate analysis need to be treated with caution due to the small-n that can be relied on, it is reassuring that these are very similar to those presented here.
} 
smaller EP party groups, the difference in their mean likelihood of defection during roll call vs. electronic voting is statistically significant at $\mathrm{p}<.05$, and almost reaches conventional levels of statistical significance for roll call vs. show of hands voting $(p=.054)$. Positive differences of .23 indicate that the voting procedure effect - being more likely to defect when voting by non-roll call - is more pronounced among MEPs belonging to the bigger EP party groups. I do not, however, find significant differences in the perceived behaviour of MEPs from countries that use open vs. closed lists for European elections, MEPs who belong to the EP party groups that are more vs. less favourable towards integration, MEPs whose national party is in government vs. opposition, or MEPs who prioritise the representation of European citizens vs. national party voters.

While no causal claims can be drawn from this, initial comparisons do suggest that certain MEPs are more likely to identify a voting procedure effect in their voting behaviour. At the very least, these analyses highlight the need for further data collection to investigate why some MEPs appear to approach representation differently when voting by non-roll call vs. roll call, while others do not.

\section{Conclusion}

While MEPs' voting behaviour is by no means a new field of study, existing research relies heavily on roll call analyses to study representation in the EP. This approach has been invaluable for enhancing our understanding of the kind of representation MEPs provide, but can only tell the full story if the behaviour of MEPs is not influenced by the voting procedure used. At the same time, a growing body of evidence demonstrates that roll call votes are not representative of all parliamentary voting occasions (e.g., Carrubba et al., 2006, 2008; Hug, 2010; Thiem, 2006).

Building on previous findings on roll call vote requests and the level of interest that different actors show in monitoring MEPs' roll call voting choices, I argue that MEPs are more likely to defect from their EP party group (in favour of their national party) when voting by show of hands or electronically instead of roll call. I further argue that differences in the role and self-perceptions of MEPs from 2004/07 accession countries and those from pre-2004 member states lead this voting procedure effect to be more pronounced among MEPs from the newer member states. I test for the presence and direction of the voting procedure effect using original MEP survey data, and find support for both arguments.

My findings contribute to our understanding of MEPs' behaviour in three ways. First, I show that roll call votes tell only part of the story with respect to how MEPs approach 
representation. While previous studies offer useful theoretical reasons and indirect evidence to suspect that roll call voting could give rise to somewhat different considerations than nonroll call voting, this study is, to my knowledge, the first empirical effort to explicitly show that many MEPs perceive differences to exist in their approach to representation when voting by show of hands or electronically, as opposed to roll call. Thus, this study highlights the need to build upon the traditional roll call analyses of MEPs' voting behaviour.

In addition, the voting procedure effect is not random, but follows a clear pattern, which helps expand our understanding of how successful the different principals - i.e., EP party groups and national parties - are in commanding loyalty from MEPs. While existing research has shown that MEPs align themselves more frequently with their national party than their EP party group during roll call voting occasions (Coman, 2009; Hix et al., 2007), the dominance of national parties as MEPs' primary principals appears to be even more pronounced when examining all parliamentary voting occasions. Because non-roll call voting is characterised by MEPs' weaker commitment to supranational representation, our existing understanding of MEPs' voting choices appears to underestimate the dominance of national parties in guiding parliamentary behaviour.

The ability of the EP party groups to command greater loyalty from their members during roll call also offers a useful suggestion regarding the EP's future development. As the EP is designed to represent cross-national interests, a greater reliance on roll call could help empower the EP party groups, and give more impetus to MEPs to approach representation in a supranational manner. This strategy is particularly useful in light of the greater likelihood of MEPs from 2004/07 accession countries to defect from their EP party group when non-call voting is used. Thus, using roll call for more voting occasions could help the EP to provide a more supranational representation of the European citizens.

Finally, my findings shed further light on the impact of the 2004/07 enlargements on the inner workings of the EP. Whereas existing roll call analyses document only relatively small differences between the voting behaviour of MEPs from 2004/07 accession countries and those from pre-2004 member states (e.g., Coman, 2009; Hix and Noury, 2009), findings presented here indicate that the differences in their parliamentary behaviour may have been underestimated; a larger proportion of MEPs from 2004/07 accession countries change their approach to representation (in favour of their national party) when voting by show of hands or electronically instead of roll call.

There are of course many aspects that influence how MEPs approach representation; MEPs' political aspirations, fractionalisation of their EP party group etc. (Farrell and Scully, 
2007, 2010; Hix et al., 2007; Meserve et al., 2009). This study represents a first-cut empirical effort to compare how MEPs approach parliamentary representation when different voting procedures are used, and therefore, adds depth to our understanding of representation in the EP. At the same time, it leaves room for (and highlights the need for) expanding this research agenda. Future research should consider the impact of voting procedures on MEPs' loyalty to their electorate vs. EP party group, explore variation in the voting procedure effect across MEPs, and look at whether the voting procedure effect remains more salient among MEPs from 2004/07 accession countries.

\section{Acknowledgements}

I would like to thank Susan Banducci, Nicole Bolleyer, and Caitlin Milazzo for their input as well as the two anonymous referees and the editors of JCMS for very detailed and thoughtful comments. Any remaining errors are the author's responsibility. 


\section{Appendix A. MEP Survey}

MEP survey sample includes 132 MEPs who disclosed their home country and 117 MEPs who disclosed their EP party group (see Table A1 below). To show that the survey sample is representative on these two major characteristics, Duncan index of dissimilarity was used. It ranges from 0 to 1 , and higher values indicate greater discrepancy between the full population and the sample (Duncan and Duncan, 1955). The comparison between the EP party groups in the sample and full population of MEPs (as of 01/01/2011) yields a value of 0.10, while the comparison of EU member states has a value of 0.15 . On these two major characteristics, the survey sample is largely representative of the general population of MEPs (see the online appendix, available at identifying website, for further steps that were taken to validate the MEP survey).

Table A1. MEP Survey Sample

\begin{tabular}{|c|c|c|c|c|c|}
\hline Country & MEPs (\%) & Sample (\%) & EP Party Group & MEPs $(\%)$ & Sample (\%) \\
\hline Austria & 2.3 & 2.3 & ALDE/ADLE & 11.8 & 11.1 \\
\hline Belgium & 3.0 & 3.1 & ECR & 7.6 & 7.7 \\
\hline Bulgaria & 2.3 & 3.1 & EFD & 4.5 & 5.1 \\
\hline Cyprus & 0.8 & 0.8 & G/EFA & 7.8 & 9.4 \\
\hline Czech Rep. & 3.0 & 4.7 & GUE-NGL & 4.9 & 10.3 \\
\hline Denmark & 1.8 & 2.3 & PPE & 37.4 & 28.2 \\
\hline Estonia & 0.8 & 1.6 & S\&D & 26.0 & 28.2 \\
\hline Finland & 1.8 & 1.6 & & & \\
\hline France & 9.8 & 7.8 & & & \\
\hline Germany & 13.5 & 15.6 & & & \\
\hline Greece & 3.0 & 2.3 & & & \\
\hline Hungary & 3.0 & 3.9 & & & \\
\hline Ireland & 1.6 & 3.9 & & & \\
\hline Italy & 9.8 & 4.7 & & & \\
\hline Latvia & 1.1 & 0.8 & & & \\
\hline Lithuania & 1.6 & 0.8 & & & \\
\hline Luxembourg & 0.8 & 0.8 & & & \\
\hline Malta & 0.7 & 0.8 & & & \\
\hline Netherlands & 3.4 & 3.9 & & & \\
\hline Poland & 6.8 & 9.4 & & & \\
\hline Portugal & 3.0 & 2.3 & & & \\
\hline Romania & 4.5 & 5.5 & & & \\
\hline Slovakia & 1.8 & 0.8 & & & \\
\hline Slovenia & 1.0 & 0.8 & & & \\
\hline Spain & 6.8 & 3.9 & & & \\
\hline Sweden & 2.4 & 3.9 & & & \\
\hline UK & 9.8 & 8.6 & \multirow{2}{*}{\multicolumn{3}{|c|}{ Duncan index $=0.10$}} \\
\hline \multicolumn{3}{|c|}{ Duncan index $=0.15$} & & & \\
\hline
\end{tabular}

Distribution of MEPs in the survey sample and in the full population (as of 01/01/2011). 


\section{References}

Ainsley, C. and Maxwell, L. (2012) 'What Can We Learn from Roll Call Votes? Strategic Signalling Incentives and the Decision to Call Roll Call Votes'. Manuscript. Andeweg, R. and Thomassen, J. (2005) 'Modes of Political Representation: Towards a New Typology'. Legislative Studies Quarterly, Vol. 30., No. 4., pp. 507-528.

André, A. and Depauw, S. (2013) 'District Magnitude and Home Styles of Representation in European Democracies'. West European Politics, Vol. 36, No. 5, pp. 986-1006.

Ansolabehere, S. and Hersh, E. (2012) 'Validation: What Big Data Reveal about Survey Misreporting and the Real Electorate'. Political Analysis, Vol. 20, No. 4, pp. 437-459.

Carey, J.M. (2009) Legislative Voting and Accountability, (Cambridge: Cambridge University Press).

Carrubba, C., Gabel, M., Murrah, L., Clough, R., Montgomery, E. and Schambach, R. (2006) 'Off the Record: Unrecorded Legislative Votes, Selection Bias and Roll-Call Vote Analysis'. British Journal of Political Science, Vol. 36, No. 4, pp. 691-704.

Carrubba, C., Gabel, M. and Hug, S. (2008) 'Legislative Voting Behaviour, Seen and Unseen: A Theory of Roll-Call Vote Selection'. Legislative Studies Quarterly, Vol. 34, No. 4, pp. 543-572.

Carrubba, C., Gabel, M. and Hug, S. (2009) Voting at the Surface: Roll Call Votes in the European Parliament. Available at «www.cis.ethz.ch/events/past_events/PEIO2009/ Carrubba_Gabel_Hug_280109».

Coman, E.E. (2009) 'Reassessing the Influence of Party Groups on Individual Members of the European Parliament'. West European Politics, Vol. 32, No. 6, pp. 1099-1117.

CCS (2013) The Comparative Candidates Survey. Available at «comparativecandidates.org». Corbett, R., Jacobs, F. and Shackleton, M. (2011) The European Parliament, (London: John Harper). 
Cowley, P. and Stuart, M. (2012) 'The Cambusters: The Conservative European Union Referendum Rebellion of October 2011'. The Political Quarterly, Vol. 83, No. 2, pp.402-406.

Deschouwer, K. and Depauw, S. (eds) (2014) Representing the People: A Survey Among Members of Statewide and Substate Parliaments, (Oxford: Oxford University Press).

Duncan, O.B. and Duncan, B. (1955) ‘A Methodological Analysis of Segregation Indexes'. American Sociological Review, Vol. 20, pp. 210-217.

EES (2012) European Parliament Election Study 2009. Available at: «www.piredeu.eu». European Parliament (2013) Plenary Sitting. Available at «www.europarl.europa. eu/plenary/en/minutes.html».

European Parliament (2014) Rules of Procedure. Available at «www.europarl.europa.eu/sides/getLastRules.do?language $=\mathrm{EN} \&$ reference $=\mathrm{TOC} »$.

Farrell, D. and Scully, R. (2007) Representing Europe's Citizens? Electoral Institutions and the Failure of Parliamentary Representation, (Oxford: Oxford University Press).

Farrell, D. and Scully, R. (2010) 'The European Parliament: One Parliament, Several Modes of Political Representation on the Ground?'. Journal of European Public Policy, Vol. 17, No. 1, pp. 36-54.

Farrell, D., Hix, S. and Scully, R. (2011) EPRG MEP Survey Dataset. Available at «Www2.lse.ac.uk/government/research/resgroups/EPRG/MEPsurvey/Data.aspx».

Finke, D. and Thiem, J. (2010) Two Principals, Two Motives: The Amendment Process and Roll Call Votes in the European Parliament. Available at «www.jhubc.it/ecpr-porto/ virtualpaperroom/133.pdf».

Gabel, M. and Carrubba, M. (2004) The European Parliament and Transnational Political Representation: Party Groups and Political Conflict. Available at «library.fes.de/pdffiles/id/02609.pdf». 
Hix, S. and Hoyland, B. (2011) The Political System of the European Union, (Basingstoke: Palgrave Macmillan).

Hix, S. and Hoyland, B. (2013) 'Empowerment of the European Parliament'. Annual Review of Political Science, Vol. 16, No. 1, pp. 171-189.

Hix, S. and Noury, A. (2009) 'After Enlargement: Voting Patterns in the Sixth Parliament'. Legislative Studies Quarterly, Vol. 34, No. 2, pp. 159-174.

Hix, S., Noury, A. and Roland, G. (2007) Democratic Politics in the European Parliament, (Cambridge: Cambridge University Press).

Hix, S., Noury, A. and Roland, G. (2013) Is there a Strategic Selection Bias in Roll Call Votes? Evidence from the European Parliament. Available at «personal.lse.ac.uk/hix/ Working_Papers/Selection_EP_3May2013.pdf».

Hoyland, B. (2010) 'Procedural and Party Effects in European Parliament Roll-Call Votes'. European Union Politics, Vol. 11, No. 4, pp. 597-613.

Hug, S. (2010) 'Selection Effects in Roll Call Votes'. British Journal of Political Science, Vol. 40, No. 1, pp. 225-235.

Hug, S. (2012) Roll Call Votes in the European Parliament. Available at «www.unige.ch/ses/ spo/static/simonhug/rcvep/rcvep.pdf».

Katz, R.S. and Mair, P. (1993) 'The Evolution of Party Organizations in Europe: The Three Faces of Party Organization'. The American Review of Politics, Vol. 14, pp. 593-617. Kreppel, A. (2002) The European Parliament and Supranational Party System, (Cambridge: Cambridge University Press).

Ladrech, R. (2007) 'National Political Parties and European Governance: The Consequences of “Missing in Action", . West European Politics, Vol. 30, No. 5, pp. 945-960. 
Lindstädt, R., Slapin, J.B. and van der Wielen, R.J. (2011) 'Balancing Competing Demands: Position-Taking and Election Proximity in the European Parliament'. Legislative Studies Quarterly, Vol. 36, No. 1, pp. 37-70.

Meserve, S.A., Pemstein, D. and Bernhard, W.T. (2009) 'Political Ambition and Legislative Behaviour in the European Parliament'. Journal of Politics, Vol. 71, No. 3, pp. 1-18. Mühlböck, M. (2012) 'National versus European: Party Control over Members of the European Parliament'. West European Politics, Vol. 35, No. 3, pp. 607-631.

Pemstein, D. (2009) Predicting Roll Calls with Legislative Text. Available at «Www.danpemstein.com/files».

Ringe, N. (2010) Who Decides and How? Preferences, Uncertainty, and Policy Choice in the European Parliament, (Oxford: Oxford University Press).

Roland. G. (2009) 'Legislative Behaviour in the European Parliament'. Economic Studies, Vol. 55, No. 1, pp. 15-29.

Saalfeld, T. (1995) ‘On Dogs and Whips: Recorded Votes'. In Döring, H. (ed) Parliaments and Majority Rule in Western Europe (New York: St Martin's Press), pp. 528-565.

Scully, R. (2005) Becoming Europeans? Attitudes, Behaviour, and Socialization in the European Parliament, (Oxford: Oxford University Press).

Scully, R., Hix, S. and Farrell, D. (2012) 'National or European Parliamentarians? Evidence from a New Survey of the Members of the European Parliament'. Journal of Common Market Studies, Vol. 50, No. 4, pp. 670-683.

Thiem, J. (2006) Explaining Roll-Call Vote Request in the European Parliament. Available at «Www.mzes.uni-mannheim.de/publications/wp/wp-90.pdf».

Thomassen, J., Noury, A. and Voeten, E. (2004) 'Political Competition in the European Parliament: Evidence from Roll Call and Survey Analysis.' In Marks, G. and 
Steenbergen, M.R. (eds) European Integration and Political Conflict (Cambridge: Cambridge University Press), pp. 141-164.

VoteWatch (2014) VoteWatch Europe. Available at «www.votewatch.eu».

Yordanova, N. and Mühlböck, M. (2014) 'Tracing the Selection Bias in Roll Call Votes:

Party Group Cohesion in the European Parliament', European Political Science Review, FirstView. 


\section{Supplementary Material}

This appendix reports supplementary material pertaining to the paper 'Voting Procedures and Parliamentary Representation in the European Parliament'. It presents an additional reliability check for the MEP survey findings and highlights why anonymity was an important element of the MEP survey, discusses the appropriateness of using MEPs' self-reported statements to capture their parliamentary behaviour, and offers a further robustness check for the findings presented in Table 5 of the article.

\section{MEP Survey - Reliability}

As part of the survey, respondents were asked about their sense of representation. The question reads: 'How important is it to you to represent the following people in the European Parliament: a) all people in Europe, b) all people in your member state, c) all people who voted for your party'; scale: 1 - of little importance, 5 - of great importance. This is a standard question incorporated within other recent surveys of MEPs, including the 2010 EPRG survey and the 2009 EES Candidate Survey (EES, 2012; Farrell et al., 2011). Therefore, it can be used as a benchmark to compare MEPs' responses in different surveys. Although one would expect some variation in MEPs' responses across the surveys due to variation in the composition of their sample and potential over-time changes, the responses should be relatively stable.

The responses, presented in Table S1, indicate that the mean scores for the three subquestions of representation are highly similar across the surveys. In addition, the comparative importance of the three categories is identical in all surveys; MEPs consistently assign primary importance to representing their national party voters, and consider European-wide interests the least important ones to represent. The MEP survey respondents' opinions do not differ meaningfully from the respondents' of other recent MEP surveys on a key question of representation. This adds further confidence in the reliability of the MEP survey findings.

Table S1. Sense of Representation in MEP Surveys

\begin{tabular}{lccc}
\hline & MEP Survey & EPRG MEP Survey & EES \\
& 2011 & 2010 & $2009^{*}$ \\
\hline All People in Europe & 3.76 & 3.64 & 3.61 \\
All People in Your Member State & 4.13 & 4.17 & 4.18 \\
All the People who Voted for Your Party & 4.17 & 4.18 & 4.37 \\
\hline
\end{tabular}

\footnotetext{
* Candidates who stood at the 2009 European election, but did not enter the EP, were excluded.
} 


\section{MEP Survey - Anonymity}

An important element of the survey was anonymity; MEPs were invited, but not required, to identify themselves. This was needed to further ensure the reliability of the MEP survey findings in light of how sensitive the issue of defection is. It has been shown that EP party groups and national parties do punish MEPs for ignoring their voting instructions, and that these punishments can have significant consequences (Hix et al., 2007; Lindstädt et al., 2011). For example, Angelika Beer who was a German Green Party MEP 2004-2009 was not put back on the party list in the 2009 European election in part for failing to demonstrate adequate support for her national party's policy stances, while high profile expulsions from the EP party groups include Roger Helmer and Hans-Peter Martin. Obtaining anonymous data does limit the scope of the paper, as one cannot study in detail how the voting procedure effect varies across different MEPs. At the same time, anonymity increases the chances that MEPs offer truthful responses on such a sensitive topic, because they can be sure that their EP party group and/or national party cannot become aware of their responses. Therefore, if they approach representation differently during the 'hidden' non-roll call voting occasions, they need not to be concerned about acknowledging it.

\section{Self-Reported Behaviour}

The reliance on self-reported statements does of course open the door for potential misrepresentation of one's actual behaviour. For example, it is widely noted that respondents are likely to over-report voter turnout in election surveys because they have an incentive to offer a socially desirable response (e.g., Ansolabehere and Hersh, 2012). While it is not possible to verify MEPs' survey responses about their behaviour during non-roll call votes, the evidence that is available suggests that these should not include systematic bias.

First, when it comes to reporting which principal MEPs prioritise, there are aspects of social desirability attached to both over-reporting one's likelihood to prioritise the EP party group (i.e., MEPs are meant to act in a supranational manner), as well as national party (i.e., national allegiances dominate MEPs' and European citizens' role and self-perceptions). As such, if the survey's anonymous nature was not sufficient to convince MEPs to offer truthful responses, which in itself is unlikely, any bias that is introduced through misrepresentation of one's behaviour should not be systematic, nor in any particular direction.

Second, where the MEP survey responses can be compared with actual voting choices (i.e., roll call voting), similar patterns emerge. The majority of MEPs claim to prioritise the voting instructions of their national party over those of their EP party group when voting by 
roll call (Table S2), which is in line with what is found by existing roll call analyses (e.g., Coman, 2009; Hix et al., 2007). Empirical evidence that is available does not indicate that MEPs' self-reported behaviour might be a misrepresentation of their actual behaviour.

Finally, MEPs' self-reported statements have been widely used to study aspects of their parliamentary activity, including their approach to representation (e.g., Bowler and Farrell, 1993; Farrell and Scully, 2010; Scully et al., 2012). Therefore, while it is impossible to be certain of the extent to which survey responses might be biased, it is reassuring that there are reasons to believe this not to be the case and that the reliance on MEPs' selfreported statements is an accepted practice for capturing their approach to representation.

Table S2. MEPs' Voting-Perceptions during Roll Call

\begin{tabular}{lc}
\hline & MEPs (\%) \\
\hline Very Unlikely (1) & 7.0 \\
Unlikely (2) & 33.8 \\
Likely (3) & 38.7 \\
Very Likely (4) & 20.4 \\
\hline Mean Score & 2.73 \\
\hline Self-perceived likelihood of prioritising one's national party over EP party group
\end{tabular}

\section{Multivariate Analysis}

In order to add a multivariate insight into the analysis, even though one needs to treat it with caution due to the small-n that can be relied on, Table S3 below presents the results of three ordered logistic regression models. The dependent variables in the models are MEPs' comparative voting behaviour during the different combinations of voting procedures, while various individual-level and contextual characteristics are included as independent variables.

The findings are very similar to those of the bivariate difference of means tests, which are shown in Table 5 of the article. In both instances, being elected from a 2004/07 accession country vs. pre-2004 member state and belonging to a big vs. small EP party group stand out as good predictors for the extent to which MEPs are more likely to defect from their EP party group when voting by non-roll call instead of roll call, with the voting procedure effect being more pronounced among MEPs from 2004/07 accession country and those belonging to a bigger EP party group. Also, no independent variable is linked to MEPs' behaviour during show of hands vs. electronic voting, as was the case in the bivariate difference of means tests. This offers further support for the findings presented in the manuscript. 
Table S3. Variation in the Voting Procedure Effect across Different MEPs

\begin{tabular}{lccc}
\hline & Model 1 & Model 2 & Model 3 \\
\hline Representation: All People in Europe & $-.20(.20)$ & $-.30(.24)$ & $.09(.22)$ \\
Representation: All People in Member State & $.44(.41)$ & $.56(.36)$ & $-.11(.69)$ \\
Representation: All People who Voted for Party & $-.14(.33)$ & $-.19(.35)$ & $-.17(.43)$ \\
Country: Entry to the EU & $1.69 * *(.61)$ & $2.14 * *(.68)$ & $.21(.79)$ \\
Country: Electoral System & $.69(.49)$ & $.55(.59)$ & $-.44(.78)$ \\
EP Party Group: Ideology & $2.09(1.13)$ & $17.77 * *(1.13)$ & $.00(1.82)$ \\
EP Party Group: Size & $-1.47 *(.69)$ & $-17.02 * *(.66)$ & $-.37(.98)$ \\
National Party: Government & $.09(.53)$ & $.60(.60)$ & $1.35(1.06)$ \\
\hline /cut1 & $-.46(2.34)$ & $-.33(2.68)$ & $-4.08(3.21)$ \\
/cut2 & $1.62(2.35)$ & $1.90(2.72)$ & $2.82(3.10)$ \\
/cut3 & $6.46(2.62)$ & $22.61(2.97)$ & 106 \\
/cut4 & $8.14(2.68)$ & & 0.05 \\
\hline Number of Observations & 106 & 106 & 0.22 \\
Pseudo R
\end{tabular}

Model 1: Ordered logit; 'roll call - show of hands' as the dependent variable; robust standard errors Model 2: Ordered logit; 'roll call - electronically' as the dependent variable; robust standard errors Model 3: Ordered logit; 'show of hands - electronically' as the dependent variable; robust standard errors Robust standard errors in parentheses; ** $\mathrm{p}<.01 ; * \mathrm{p}<.05$ 